\title{
BMJ Open Use of targeted mobile X-ray screening and computer-aided detection software to identify tuberculosis among high-risk groups in Romania: descriptive results of the E-DETECT TB active case- finding project
}

\author{
Beatrice Mahler, ${ }^{1}$ Gerard de Vries (1) , ${ }^{2,3}$ Rob van Hest, ${ }^{4,5}$ Dan Gainaru, ${ }^{1}$ \\ Dee Menezes, ${ }^{6}$ Gilda Popescu, ${ }^{1}$ Alistair Story, ${ }^{7,8}$ Ibrahim Abubakar (i) ${ }^{9}$
}

To cite: Mahler B, de Vries G, van Hest $\mathrm{R}$, et al. Use of targeted mobile $\mathrm{X}$-ray screening and computer-aided detection software to identify tuberculosis among high-risk groups in Romania: descriptive results of the E-DETECT TB active case-finding project. BMJ Open 2021;11:e045289. doi:10.1136/ bmjopen-2020-045289

- Prepublication history for this paper is available online. To view these files, please visit the journal online (http://dx.doi org/10.1136/bmjopen-2020045289).

$\mathrm{BM}$ and GdV contributed equally.

Received 02 October 2020 Accepted 07 August 2021

Check for updates

(c) Author(s) (or their employer(s)) 2021. Re-use permitted under CC BY-NC. No commercial re-use. See rights and permissions. Published by BMJ.

For numbered affiliations see end of article.

Correspondence to Prof Ibrahim Abubakar; i.abubakar@ucl.ac.uk

\section{ABSTRACT}

Objective To implement and assess the mobile X-ray unit (MXU) equipped with digital radiography, computer-aided detection (CAD) software and molecular point of care tests to improve early tuberculosis (TB) diagnosis in vulnerable populations in a TB outreach screening programme in Romania.

Design Descriptive study.

Settings Prisons in Bucharest and other cities in the southern part of Romania, homeless shelters and services for problem drug users in Bucharest, and Roma populations in Bucharest and Craiova.

Participants 5510 individuals attended the MXU service; 5003 persons were radiologically screened, $61 \%$ prisoners, $15 \%$ prison staff, $11 \%$ Roma population, $10 \%$ homeless persons and/or problem drug users and $3 \%$ other.

Interventions Radiological digital chest X-ray (CXR) screening of people at risk for TB, followed by CAD and human reading of the CXRs, and further TB diagnostics when the pulmonologist classified the CXR as suggestive for TB.

Primary and secondary outcome measures Ten bacteriologically confirmed TB cases were identified translating into an overall yield of 200 per 100000 persons screened (95\% Cls of 109 to 368 per 100 000). Prevalence rates among homeless persons and/or problem drug users (826/100 000; 95\% Cl 326 to 2105/100 000) and the Roma population (345/100 000; 95\% Cl 95 to 1251/100 000) were particularly high.

Results The human reader classified $6.4 \%(n=317)$ of the CXRs as suspect for TB (of which 32 were highly suggestive for TB); $16.3 \%$ of all CXRs had a CAD4TB version 6 score $>50$. All 10 diagnosed TB patients had a CAD4TB score $>50 ; 9$ had a CAD4TB score $>60$.

Conclusions Given the high TB prevalence rates found among homeless persons and problem drug users and in the Roma population, targeted active case finding has the potential to deliver a major contribution to TB control in Romania.

\section{Strengths and limitations of this study}

- An innovative mobile digital X-ray unit with computer-aided detection was successfully implemented to screen socially excluded groups in Romania, the country with the highest tuberculosis (TB) incidence in the European Union (EU).

- A limitation of our study was the limited number of risk-group individuals screened (in total 5003), due to delays in project initiation.

- Another limitation was the fact that prisoners were often already screened with a chest $X$-ray on detention.

- An important spin-off of the Early DETECTion of Tuberculosis project was awareness raising for TB and active case-finding in Romania. The project served as a stepping stone for its successor funded by EU Structural Funds.

\section{INTRODUCTION}

Tuberculosis (TB) in the European Union (EU) and European Economic Area (EEA) is a public health problem that disproportionately affects certain, often socially marginalised, risk groups. ${ }^{1}$ Vulnerable and hard-to-reach populations at risk for TB include: homeless persons or people with a history of homelessness, highrisk problem drug users, people with problematic alcohol use, people in prison or in enforced segregation, some vulnerable migrant populations who are excluded from health and social care services and other marginalised, poor and remote groups, such as Roma populations. ${ }^{23}$ According to the European Centre for Disease Prevention and Control, interventions in vulnerable groups are key to eliminating TB in Europe and in the context of the WHO End TB Strategy. ${ }^{45}$ For early detection of TB 
cases among social risk groups, outreach active case finding (ACF) activities are indispensable, possibly combining TB screening with diagnosis of other common, possibly lifethreatening, comorbidities, for which an effective treatment is available. ${ }^{67}$ To address the high disease burden of TB in vulnerable EU populations the Early DETECTion of Tuberculosis (E-DETECT TB) consortium was formed in 2016, funded by the European Commission. ${ }^{1}$ E-DETECT TB uses evidenced-based approaches targeting vulnerable populations, including recent migrants to the EU, homeless persons, prisoners, problem drug users and those with MDR-TB, to address one of the cornerstones of TB control: early case detection and initiation and completion of treatment of TB or latent TB infection.

E-DETECT TB in Romania focuses on ACF in vulnerable groups. Romania has the highest TB burden in the EU/ EEA with almost a quarter $(23.1 \%)$ of the reported patients in 2018, and a TB notification rate six times higher than the EU/EEA average. ${ }^{8}$ Although the overall TB notification rates in Romania declined from 142/100 000 population in 2002 to $63 / 100000$ population in 2018 , in absolute numbers from 30065 cases to 12205 cases respectively, TB remains a major public health problem. ${ }^{89}$ Despite the decline in TB incidence in the general population, rates are still high in certain vulnerable groups, with often a higher risk of exposure due to lifestyle, a greater risk of progression to active disease due to comorbidities and poor health, or having limited access to healthcare services. ${ }^{9} 10$ The E-DETECT TB project aims to apply innovative diagnostic tools, such as a mobile X-ray unit (MXU), equipped with digital radiography with computer-aided detection $(\mathrm{CAD})$ and rapid bacteriological tests, such as the Xpert MTB/RIF, to improve early TB diagnosis in these socially excluded groups. ${ }^{13^{11-13}}$ It further aims to strengthen care integration using an outreach strategy providing a 'onestop shop' clinic, bringing together all required diagnostic procedures, social support, peer support and close links to non-governmental organisations (NGOs) and the national TB programme (NTP), to ensure not only treatment initiation but also treatment completion. ${ }^{14}$

We describe the implementation and assessed the yield, the bacteriological results and treatment outcome findings of the E-DETECT TB active case-finding project in Romania and compared the results of CAD to human reading in the algorithm used.

\section{METHODS}

\section{Study design and period}

Descriptive study based on operational research during a TB control intervention, planned between November 2016 and May 2019, but effectively implemented between August 2018 and September 2019 in Bucharest and several other places in Romania.

\section{Mobile X-ray unit}

Building a functional MXU mainly concentrated on procurement of a truck, X-ray equipment with CAD software (CAD4TB, Delft Imaging Systems, 's-Hertogenbosch, the Netherlands) and Xpert MTB/RIF (Cepheid, Sunnyvale, California, USA) equipment, and developing the information technology-system. Turning these components into an operational MXU proved challenging for various unanticipated technical, administrative and legal reasons (box 1). The postponements reduced the effective screening period to 14 months (August 2018 through September 2019), instead of the 24 months projected. In the meantime, training and exchange of experience were performed.

\section{Reading of chest X-rays and sputum collection for rapid diagnosis}

All chest X-rays (CXRs) were read by the CAD4TB software (version 5, updated to version 6 in June 2019) in the MXU within $30 \mathrm{~s}$ during screening, and within 1-2 days

\section{Box 1 Equipped and functioning mobile X-ray unit}

\section{Process of building a functioning mobile $X$-ray unit}

Building a functional (mobile $X$-ray unit) MXU mainly concentrated on procurement of a truck, X-ray equipment with computer-aided reading software (CAD4TB, Delft Imaging Systems, Veenendaal, the Netherlands) and Xpert MTB/RIF (GeneXpert, Cepheid, Sunnyvale, California, USA) equipment, optimisation of the information technology-system and turning these components into an operational MXU. This process proved challenging for various unanticipated technical, administrative and legal reasons. Technical delays were encountered because the building of the truck took longer than initially estimated, as some essential parts were supplied late, and the specifications set by the responsible Romanian authorities had to be met. Administrative and legal delays occurred when the procurement law in Romania was updated in May 2016, the first month of project implementation, and acquisition of the truck had to be postponed until the new system was functional. Final inclusion of cofinancing of the project in the Romanian State budget, including discussions with the European Commission Consumers, Health, Agriculture and Food Executive Agency around depreciation of equipment costs during the project lifetime, also took more time than expected, as well as other agreements. Further postponements for legal reasons were met when early 2018 the Romanian legislation of the National Commission for Nuclear Activities Control (CNCAN) was updated, influencing timely authorisation. Final permissions of the Department of Public Health and CNCAN were received mid-July 2018, and on 31 July 2018 the first homeless persons in Bucharest were screened. The cascade of postponements reduced the effective screening exercise to 14 months (August 2018 through September 2019), instead of the 24 months projected.

\section{Exchange and training}

In the second year of the project international experience with MXU TB screening practices among problem drug users and homeless persons, including case holding activities, were shared with Romanian pulmonologists and the use and experience with the application of CAD4TB software and other innovative TB diagnostics discussed. Romanian MXU staff and representatives of non-governmental organisation partners participated in a 1 week exchange visit to the Find\&Treat team in London, UK, and, on completion of the MXU, the radiographers were trained in the use of the $\mathrm{X}$-ray equipment. 
by a chest physician, with 20 years experience in reading CXRs for TB screening (DG). CAD4TB provides a score of 1-100 to each image, with 1 meaning not suspect for TB and 100 highly suspicious for TB. It was planned, that all clients with a CAD4TB score above the threshold set by the supplier would be requested to produce sputum for on-the-spot examination with the GeneXpert around the MXU or in prisons. Biosafety requirements in Romania however prevented this fast-track algorithm and Xpert testing was requested by the TB physician on indication after reading the CXRs.

For structured interpretation of the CXRs by the human reader a modified classification system was agreed ${ }^{15}$ : normal, no abnormalities detected (\#0); abnormal, findings highly suggestive for active $\mathrm{TB}$, warranting immediate action, for example, isolation of the patient in case of cavities or extensive infiltrative disease (\#1); abnormal, findings possibly suggestive for active TB, including all TB sequalae, action required to confirm or rule out TB (\#2); abnormal findings not suggestive for active TB including all other radiological findings suggesting other pulmonary diseases (eg, silicosis, pneumothorax), heart diseases (cardiomegaly), fractures, scoliosis, but also nondisease related CXR findings such as azygos lobe, bullet or shrapnel, pacemaker and so on, either warranting further action such as clinical examination or referral (\#3a) or no further action required (\#3b). The CAD4TB scores were grouped into three categories, based on the two threshold scores (50 and 60) commonly advised by the supplier, to compare the results with the human reading.

\section{Risk group definitions and analysis}

In the first 2 years of the project, an analysis of vulnerable risk groups for TB was performed using the Romanian NTP TB register. ${ }^{16}$ Risk group definitions are described elsewhere. ${ }^{17} 18$ Estimated TB notification rates among prisoners, problem drug users and homeless persons in 2015-2017 were high with 535, 570 and 1220 per 100000 individuals, respectively.

\section{Statistical analysis}

All results are expressed as proportions. The prevalence rates were calculated for each risk group by dividing the yield with the number of people screened per 100.000 people. CIs were calculated using the Wilson score given some of the smaller cell sizes.

\section{Patient and public involvement statement}

Patients were not involved in the project; NGOs in Romania were involved in the implementation and evaluation of the project and dissemination of project results.

\section{RESULTS}

\section{Demographic and clinical characteristics}

A total of 5510 individuals attended the MXU service between August 2018 and September 2019 (figure 1). Of these 507 persons had a CXR taken in the previous months (mainly in the prison population) or declined to cooperate with radiographic screening, leaving 5003 persons screened with a CXR: $61 \%$ prisoners, $15 \%$ prison staff, $11 \%$ Roma population, $10 \%$ homeless persons and/or problem drug users and 3\% other (table 1). The total number of MXU screening days was 159, which gives an average of 31 CXRs per screening session.

Of those attending the MXU, 4325 (78\%) individuals were male; 5427 (98\%) persons were born in Romania and 2955 (54\%) were aged between 25 and 45 years. According to self-reporting, 150 (2.7\%) individuals had previously TB, 2571 (47\%) persons were tested for HIV (of which $26(1.0 \%)$ indicated to be seropositive) and 2608 $(47 \%)$ attendees were previously tested for hepatitis C virus, of which $266(10.2 \%)$ reported a positive test result. Of the symptomatic attendees $165(3.0 \%)$ reported symptoms of cough (9 $(0.2 \%)$ with haemoptysis), 124 (2.3\%) weight loss, $141(2.6 \%)$ night sweats and $37(0.7 \%)$ fever, respectively.

\section{CAD4TB scores of CXRs and classification of the human reader}

A total of 4996 CAD4TB reading results were available for analysis (seven images had a negative score). The CAD4TB version 5 software gave 23\% (805/3,441; four had a negative score) of the CXRs a score above $50 \%$ and $8.5 \%(294 / 3441)$ a score above 60 . The CAD4TB version 6 (since July 2019) gave 17\% (266/1555; three had a negative score) of the CXRs a score above $50 \%$ and $4.8 \%(75 / 1555)$ a score above 60 . All CXRs with a $\mathrm{CAD} 4 \mathrm{~TB}$ version 5 reading were re-read with $\mathrm{CAD} 4 \mathrm{~TB}$ version 6 . The distribution of these all-version- 6 scores is displayed in table 2 and figure $2: 16.3 \%(815 / 5000)$ of the CXRs had a score above $50 \%$ and $5.2 \%(258 / 5000)$ a score above 60 .

The human reader classified $4507(90.1 \%)$ CXRs as normal; $32(0.6 \%)$ as highly suspicious for active TB; $285(5.7 \%)$ with a low suspicion for active TB, including abnormalities that could be explained by a previous TB episode and $176(3.5 \%)$ individuals with other CXR findings not suggestive for TB, of which $24(0.5 \%)$ needed further investigation (figures 1 and 2).

A CAD4TB cut-off of 50 would include all 32 persons $(100 \%)$ with CXR abnormalities classified by the human reader as 'highly suspicious for active TB' and 222/286 $(78 \%)$ of the individuals classified as 'low suspicion for active TB'. Increasing the cut-off to 60 would include 29/32 (91\%) persons classified by the human reader as 'highly suspicious for active TB' and 138/286 (48\%) of the individuals classified as 'low suspicion for active TB'.

\section{GeneXpert examinations}

In 154 of the 317 (49\%) persons with a CXR abnormality suggestive for $\mathrm{TB}$ according to the human reader GeneXpert testing was performed (n-140) or attempted $(\mathrm{n}=14) ; 11(8 \%)$ individuals had a positive result and 


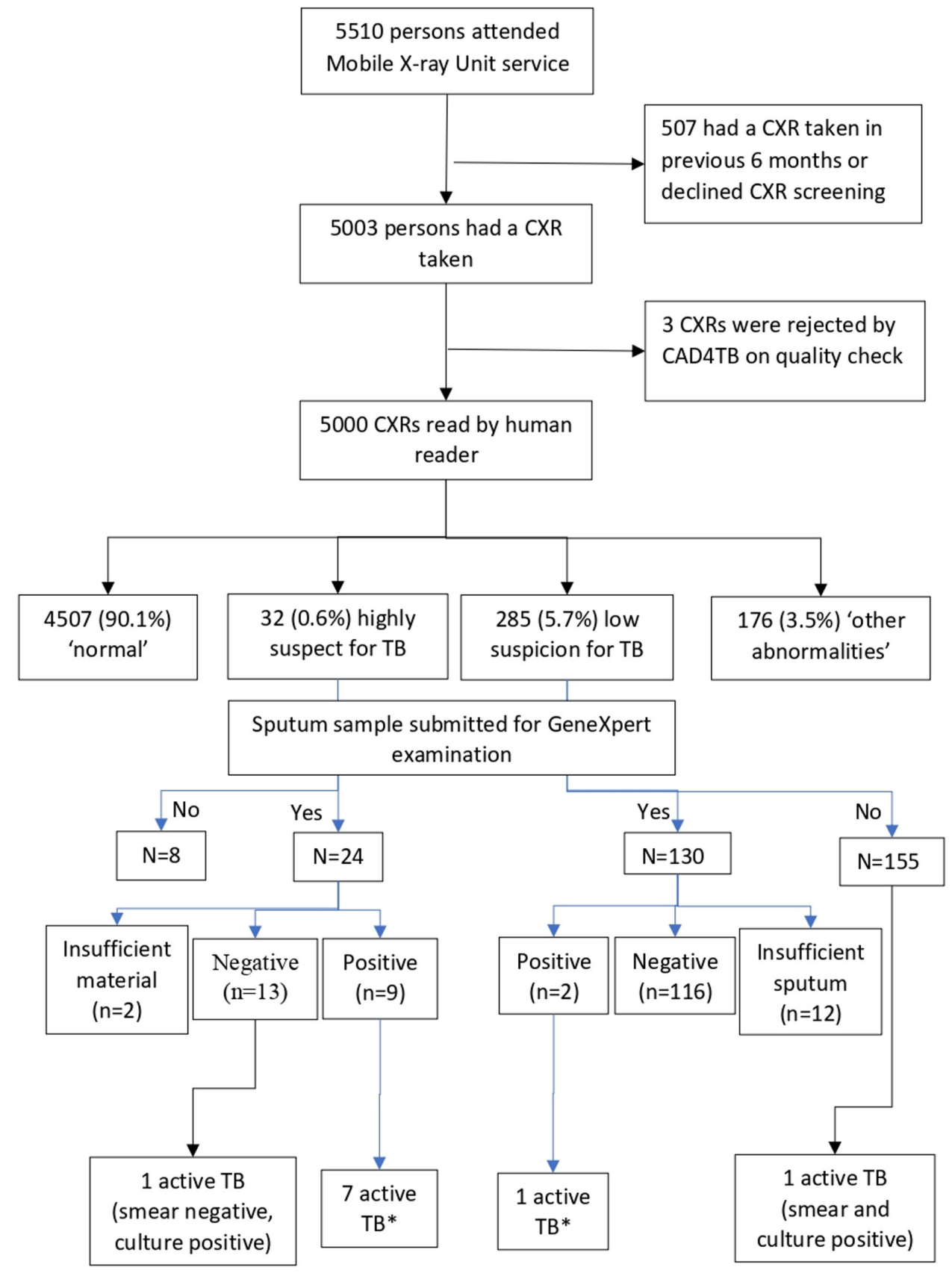

* Active TB was not confirmed in two persons and one person. All three had negative Mycobacterium tuberculosis cultures and had been treated for TB in the past.

Figure 1 Flow chart of study profile of tests and results. CXR, chest X-ray; TB, tuberculosis.

$129(92 \%)$ a negative result (figure 1). In three persons with a 'low' positive GeneXpert result, that is, a low number of Mycobacterium tuberculosis genomic copies detected, all with a registered previous TB episode, cultures for $M$. tuberculosis were negative, and a new diagnosis of active TB was not established. All positive GeneXpert test results were obtained in clients with a CAD4TB score $>60$, all but one having a score $>70$.

In $162(51 \%)$ persons no specimen was received for investigation, because CXRs were read later and some clients could not be traced anymore, or due to the absence of productive cough.

The CXR of one person was highly suspicious for active TB according to the human reader but the GeneXpert testing and sputum smear microscopy were negative. However, the culture for $M$. tuberculosis became positive. In one person with a CXR with a low suspicion for TB according to the human reader and a CAD4TB score of 80 , GeneXpert testing was not performed but sputum smear microscopy and culture were positive. Thus, the 
Table 1 Number of people belonging to various tuberculosis (TB) risk groups attending the mobile X-ray unit in Romania and number of people screened with a chest X-ray

\begin{tabular}{|c|c|c|c|c|}
\hline \multirow{2}{*}{$\begin{array}{l}\text { Risk-group } \\
\text { population }\end{array}$} & \multicolumn{2}{|c|}{ Attendances } & \multicolumn{2}{|c|}{ Chest X-rays } \\
\hline & $\mathbf{n}$ & $\%$ & $\mathbf{N}$ & $\%$ \\
\hline Prisoners & 3543 & 64 & 3077 & 61 \\
\hline $\begin{array}{l}\text { Homeless } \\
\text { persons and/or } \\
\text { problem drug } \\
\text { users }\end{array}$ & 503 & 9 & 484 & 10 \\
\hline $\begin{array}{l}\text { Roma } \\
\text { population }\end{array}$ & 589 & 11 & 579 & 11 \\
\hline $\begin{array}{l}\text { Staff (mostly } \\
\text { prison staff) }\end{array}$ & 742 & 14 & 733 & 15 \\
\hline $\begin{array}{l}\text { General } \\
\text { population }\end{array}$ & 133 & 2 & 130 & 3 \\
\hline Total & 5510 & 100 & 5003 & 100 \\
\hline
\end{tabular}

*A new category 'staff' was made in the database on 10 October 2018. Before that date (prison) staff were also screened but recorded under prisoners, artificially lowering the TB prevalence rate among true prisoners.

total number of TB patients diagnosed in the E-DETECT project was 10 .

\section{Bacteriologically confirmed TB diagnoses and treatment outcome monitoring}

A summary of the results of the 10 diagnosed TB patients is given in table 3, with risk group, human reader classification and CAD4TB score. Seven had culture-confirmed disease. No rifampicin resistance was identified by GeneXpert or culture.

Out of the ten persons diagnosed with active TB seven started treatment. So far (August 2020), six have completed treatment and one was still on treatment. Three individuals were lost-to-follow-up: one left the hospital after 1 day and two could not be traced after the positive GeneXpert test. All were sputum-smear and culture-negative and had a (very) low GeneXpert result.

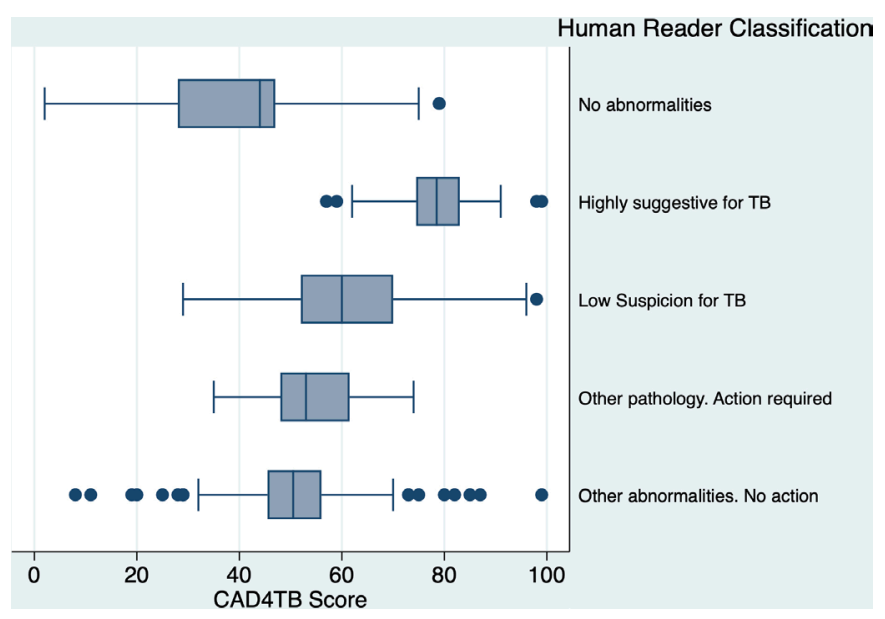

Figure 2 Box plot comparing the human reader classification of the chest X-rays and the CAD4TB scores (version 6). CXR, chest X-ray; TB, tuberculosis.

\section{TB prevalence in the vulnerable TB risk groups}

The yield of screening within the E-DETECT project is shown in table 4 per risk population and other individuals examined. The highest prevalence rates were found among homeless persons and/or drug users and the Roma population, with 826/100 000 screened and $345 / 100000$ screened respectively. The prevalence rate found among prisoners was relatively low (97 per 100000 screened). Screening of prison staff $(n=733)$ did not identify a single TB patient. Since the number of patients identified is very small, CIs around the prevalence rates are very wide.

The yield of screening might be higher if the algorithm of bacteriological testing on request of the human reader was strictly followed. All CXRs suggestive for TB according to the human reader but without bacteriological testing performed were reanalysed and discussed by an expert panel (DG, GdV and $\mathrm{RvH}$ ). The panel concluded that pulmonary $\mathrm{TB}$ was still highly suspect in one homeless person and one person from the Roma community (CAD4TB scores 75 and 66, respectively).

Table 2 Comparison of the human reader classification of the CXRs and the CAD4TB scores (version 6)

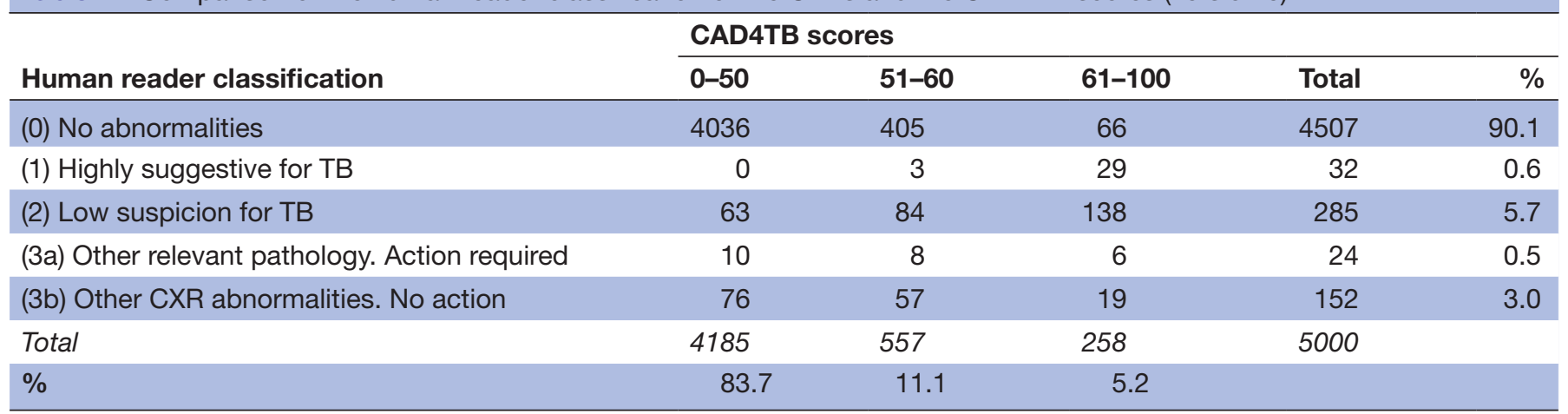

CXR, chest X-ray; TB, tuberculosis. 
Table 3 Bacteriological results by tuberculosis risk group, diagnosis and treatment outcomes

\begin{tabular}{|c|c|c|c|c|c|c|c|}
\hline Risk group & $\begin{array}{l}\text { Human reader } \\
\text { classification }\end{array}$ & $\begin{array}{l}\text { CAD4TB } \\
\text { score* }\end{array}$ & $\begin{array}{l}\text { Sputum smear } \\
\text { microscopy } \\
\text { result (ZN) }\end{array}$ & Xpert result† & $\begin{array}{l}\text { Culture } \\
\text { result }\end{array}$ & Diagnosis & Treatment \\
\hline Prisoner & 1 (high suspicion) & $55(59)$ & Negative & Negative & Positive & Active TB & Cured \\
\hline Homeless & 1 (high suspicion) & $93(83)$ & Positive & High & Positive & Active TB & Cured \\
\hline Prisoner & 1 (high suspicion) & $89(79)$ & Negative & Low & Positive & Active TB & Cured \\
\hline Prisoner & 2 (low suspicion) & $71(66)$ & Negative & Low & Negative & $\begin{array}{l}\text { No (relapse) } \\
\text { TB }\end{array}$ & No \\
\hline Homeless & 1 (high suspicion) & 79 (76) & Negative & Low & Positive & Active TB & Completed \\
\hline $\begin{array}{l}\text { General } \\
\text { population }\end{array}$ & 2 (low suspicion) & $67(64)$ & Negative & Low & Positive & Active TB & Cured \\
\hline $\begin{array}{l}\text { Roma } \\
\text { population }\end{array}$ & 1 (high suspicion) & $77(74)$ & Negative & Low & Negative & Active TB & $\begin{array}{l}\text { Lost to follow- } \\
\text { up }\end{array}$ \\
\hline Homeless & 1 (high suspicion) & $97(88)$ & Negative & Low & Negative & Active TB & $\begin{array}{l}\text { Lost to follow- } \\
\text { up }\end{array}$ \\
\hline Homeless & 1 (high suspicion) & 79 (75) & Negative & Scarce & Negative & Active TB & $\begin{array}{l}\text { Lost to follow- } \\
\text { up }\end{array}$ \\
\hline Prisoner & 1 (high suspicion) & 78 & Negative & Low & Positive & Active TB & Cured \\
\hline $\begin{array}{l}\text { Roma } \\
\text { population }\end{array}$ & 1 (high suspicion) & 81 & Negative & Low & Negative & $\begin{array}{l}\text { No (relapse) } \\
\text { TB }\end{array}$ & No \\
\hline $\begin{array}{l}\text { Roma } \\
\text { population }\end{array}$ & 1 (high suspicion) & 91 & Negative & Low & Negative & $\begin{array}{l}\text { No (relapse) } \\
\text { TB }\end{array}$ & No \\
\hline $\begin{array}{l}\text { Roma } \\
\text { population }\end{array}$ & 2 (low suspicion) & 80 & Positive & $\begin{array}{l}\text { Not } \\
\text { performed }\end{array}$ & Positive & Active TB & $\begin{array}{l}\text { Still on } \\
\text { treatment }\end{array}$ \\
\hline
\end{tabular}

*In parentheses the CAD4TB version 6 score of CXRs originally read by the CAD4TB version 5 . The last four CXRs were read by CAD4TB version 6 already.

†(Very) low: (very) low semi-quantitation level, that is, a (very) low number of Mycobacterium tuberculosis genomic copies detected.

CXR, chest X-ray; TB, tuberculosis; ZN, Ziehl-Neelsen.

\section{DISCUSSION}

After an MXU with CAD software was procured, authorised and operational, a total of 5003 individuals were radiologically screened, including 484 homeless persons

Table 4 Number of individuals screened with CXR, number of TB diagnoses made and yield per vulnerable population group screened

\begin{tabular}{|c|c|c|c|}
\hline Population & $\begin{array}{l}\text { Number } \\
\text { screened } \\
\text { with CXR }\end{array}$ & TB & $\begin{array}{l}\text { Prevalence per } \\
100000(95 \% \text { Cls })\end{array}$ \\
\hline Prisoners & 3077 & 3 & 97 (33 to 286 ) \\
\hline $\begin{array}{l}\text { Homeless } \\
\text { persons and/or } \\
\text { problem drug } \\
\text { users }\end{array}$ & 484 & 4 & 826 (322 to 2105) \\
\hline $\begin{array}{l}\text { Roma } \\
\text { population }\end{array}$ & 579 & 2 & 345 (95 to 1251) \\
\hline Staff & 733 & 0 & $0(0$ to 521$)$ \\
\hline $\begin{array}{l}\text { General } \\
\text { population }\end{array}$ & 130 & 1 & 769 (140 to 4220$)$ \\
\hline Total & 5003 & 10 & 200 (109 to 368) \\
\hline
\end{tabular}

CXR, chest X-ray; TB, tuberculosis. and/or problem drug users and 579 Roma population. The human reader classified 317 (6.4\%) CXRs as suspect for TB (of which 32 highly suspect) and 815 (16.3\%) CXRs had a CAD4TB score >50. A CAD4TB cut-off of 50 would include all 32 persons $(100 \%)$ with CXR abnormalities classified by the human reader as 'highly suspicious for active TB'. We found ten bacteriologically confirmed $\mathrm{TB}$ cases, of which seven were culture-confirmed, translating into a prevalence rate among homeless persons and/or problem drug users and the Roma population of 826/100 000 and 345/100 000 screened respectively, underpinning the justification of targeted screening in certain risk groups in Romania.

The first objective of the E-DETECT TB project, to ensure early TB diagnosis in certain vulnerable populations with innovative diagnostic tools, using a MXU equipped with digital radiography, automated X-ray reading software and rapid molecular diagnostics, could only be met partially. Due to the late delivery of an operational MXU the period for outreach was 14 months instead of the planned 24 months; effective screening time was also less, for technical and logistical problems among other issues. Systematic screening of vulnerable populations with a modern MXU has been applied in 
other EU countries. Different backgrounds influenced initial implementation. When in 2002 screening of specific urban TB risk groups started in Rotterdam, the Netherlands, the country already had years of experience using a fleet of modern MXUs to screen asylum seekers and prisoners, facilitating application of a local intervention. ${ }^{19}$ However, when in 2005 a similar project started in London (Find\&Treat; https://www.ucl. ac.uk/tb/research-and-publications/uclh-find-treatservice), in the UK mass miniature MXU screening for TB was abandoned for decades and during the built-up of know-how and skills in the first years Find\&Treat experienced an episode of 'Find\&Loose'. ${ }^{20}$ Today, it is probably the most advanced and innovative TB control initiative of ACF in urban high-risk vulnerable populations in Europe. ${ }^{1420-22}$

The daily attendance in the MXU in the E-DETECT TB project was less than anticipated, for example, due to certain prison regulations or apparently insufficient awareness raising activities. A referenced summary of factors contributing to improved TB screening uptake among TB risk groups, such as adequate accommodation, incentives, TB health education and TB screening promotion, involvement of social workers and cooperation between various services working with similar vulnerable individuals, is described elsewhere. ${ }^{23}$ In retrospect, targeting vulnerable groups with the highest risk for active intrathoracic TB was sub-optimal.

For biosafety reasons, collection of sputum in the MXU and in the prisons was not allowed. For operational reasons the algorithms of sputum collection according to a predefined CA4TB score or (later) requested by the human reader could not be strictly implemented. To overcome the biosafety issues of performing Xpert MTB/RIF in the MXU, recently a novel, extremely lowcost solution has been described using a septum sample pot. ${ }^{12}$

The human reader and a CAD4TB score $>50$ were both able to detect all diagnosed TB cases; with a CAD4TB score of $>60$ all but one of the TB cases would be detected. An alternative algorithm is to only have a human reading of CXRs with CAD4TB scores $>50$. This would have prevented human reading of $84 \%$ of the CXRs and 63 bacteriological investigations, without missing a single TB patient, although the numbers in our study are small for robust conclusions. The pulmonologist in our project was aware of the CAD4TB results in classifying the CXRs. A separate study was performed to compare human reading with computer-automated reading, in which three human readers were blinded for the CAD4TB score and this study confirmed that human reading could be reduced to less than $20 \%$ of the screening CXRs while maintaining high sensitivity. ${ }^{24}$

The literature on CAD usually addresses diagnostic accuracy by comparison with human readers or bacteriological standards and chosen CAD cut-off values may vary depending on trading-off sensitivity versus specificity. A retrospective evaluation of almost 40000 CXRs with CAD4TB from the Find\&Treat database showed that $55.7 \%$ of the CXRs would not need human double-reading, at a sensitivity of $95 \% .^{13}$ A retrospective evaluation of CXRs from outpatients in Nepal and Cameroon, using three CAD systems for detecting TB-associated abnormalities, showed that the number of Xpert MTB/RIF tests could be reduced by $66 \%$ by CAD, while maintaining sensitivity at $95 \%$ or higher. ${ }^{25}$ In South Africa, prescreening with CAD, limiting Xpert testing, would reduce costs substantially and increase daily throughput, while maintaining high sensitivity. ${ }^{26} \mathrm{~A}$ systematic review published in 2016 concluded that the evidence of diagnostic accuracy of CAD was still limited by the small number of studies and not generalisable to low TB and HIV settings. ${ }^{27}$

A limitation of our study is, as mentioned, the limited number of risk-group individuals screened, due to delays in project initiation, shortening the screening period from 24 months to 14 months, and screening 5003 individuals instead of the 25000 planned. Another limitation was targeting the vulnerable populations most at risk. In Romania prisoners are often screened with a CXR on detention, which is reflected in the relatively low prevalence of active TB of 97/100 000 screened persons found in this project, lower than the prevalence based on notified TB patients in prisoners for 20152017 (535/100 000). ${ }^{16}$ Furthermore, 863 persons not belonging to a defined risk group were screened. Within the limitations of the few TB cases identified through this E-DETECT TB project, the prevalence rates found among homeless persons and problem drug users correspond with the estimated TB notification rates based on routine surveillance data 2015-2017, that is, 1220/100 000 and 570/100 000, respectively. ${ }^{16}$ Another limitation is that, due to the low number of TB patients diagnosed, the second objective of the E-DETECT TB project, to strengthen care integration, could not be tested. However, the Marius Nasta Institute had several meetings with prison authorities and NGOs working with homeless people, intravenous drug users and Roma populations. This led to a formal agreement with the National Administration of Penitentiaries and non-formal agreements with some NGOs. An important spin-off of the E-DETECT TB project was awareness raising for TB and ACF in Romania through the presence and services of MXU during various events throughout the project, at times attended by government representatives such as the Minister of Health. The project served as a stepping stone for its successor, POCU 4.9 (Programul Operațional Capital Uman (Human Resource Operational Programme, Ministry of European Funding, Bucharest, Romania). This project is funded by EU Structural Funds and was launched in November 2019, aiming to screen 75000 individuals nationwide in Romania in 3 years' time, using an additional three MXUs.

In conclusion, we found 10 bacteriologically confirmed TB cases among 5003 individuals screened 
with a CXR, translating in an overall prevalence of 200/100 000 screened. Given the high TB incidence rates among homeless persons and problem drug users, and in the Roma population, as our results suggests, ACF has the potential to deliver a major contribution to TB control and elimination in Romania, benefitting both TB risk groups as well as the general population.

\section{Author affiliations}

${ }^{1}$ Department of Pulmonoloy, Institute for Lung Diseases Marius Nasta, Bucuresti, Romania

${ }^{2}$ Team The Netherlands \& Elimination, KNCV Tuberculosis Foundation, Den Haag, Zuid-Holland, The Netherlands

${ }^{3}$ Centre for Infectious Disease Control, National Institute for Public Health and the Environment, Bilthoven, The Netherlands

${ }^{4}$ Department of Lung Diseases and Tuberculosis, University Medical Centre Groningen, Groningen, The Netherlands

${ }^{5}$ Department of Tuberculosis Control, Public Health Service, Groningen, The Netherlands

${ }^{6}$ Public Health Data Science, UCL Institute of Health Informatics, London, UK ${ }^{7}$ Find\&Treat, University College London Hospitals NHS Foundation Trust, London, UK ${ }^{8}$ Institute of Health Informatics, University College of London, London, UK

${ }^{9}$ Institute for Global Health, University College London, London, UK

Acknowledgements The authors gratefully acknowledge the E-DETECT TB (709624) project which has received funding from the European Union's Health Programme (2014-2020). The views expressed here are the authors only and are their sole responsibility; it cannot be considered to reflect the views of the European Commission and/or the Consumers, Health, Agriculture and Food Executive Agency or any other body of the EU.Delft Imaging was a co-applicant on the EU grant that supported the project which required all partners to co-fund their contribution.

Contributors Study design: GdV, GP, AS and IA. Funding acquisition: GdV, GP, AS and IA. Data analysis: BM, GdV, RvH, DG, DM and AS. Manuscript drafting: GdV and RvH. Critical manuscript review: BM, DG, DM, AS and IA. All authors read and approved the final manuscript.

Funding The E-DETECT TB project has received funding from the European Commission Consumers, Health, Agriculture and Food Executive Agency (grant number: 709624). Funding information for this article has been deposited with the Crossref Funder Registry.

Competing interests IA reports grants from European Commission to undertake the project reported in this manuscript.

Patient and public involvement Patients and/or the public were involved in the design, or conduct, or reporting, or dissemination plans of this research. Refer to the Methods section for further details.

Patient consent for publication Not required.

Ethics approval In this study routinely collected data, fully anonymised and obtained with consent, from a service provision in Romania, was analysed. Ethics approval for the storage and process of the data at the University College London (UCL) were obtained from the UCL ethics committee. The scientific advisory board which includes an ethics subcommittee also reviewed and agreed the project. The Data Protection Committee of the Institute for Lung Diseases Marius Nasta, Bucharest, Romania, approved the project and use of data for this study under Reg. Nr. 20276.

Provenance and peer review Not commissioned; externally peer reviewed.

Data availability statement Data are available upon reasonable request. (by emailing the author for correspondence).

Open access This is an open access article distributed in accordance with the Creative Commons Attribution Non Commercial (CC BY-NC 4.0) license, which permits others to distribute, remix, adapt, build upon this work non-commercially, and license their derivative works on different terms, provided the original work is properly cited, appropriate credit is given, any changes made indicated, and the use is non-commercial. See: http://creativecommons.org/licenses/by-nc/4.0/.

\section{ORCID iDs}

Gerard de Vries http://orcid.org/0000-0003-1278-4503

Ibrahim Abubakar http://orcid.org/0000-0002-0370-1430

\section{REFERENCES}

1 Abubakar I, Matteelli A, de Vries G, et al. Towards tackling tuberculosis in vulnerable groups in the European Union: the E-DETECT TB Consortium. Eur Respir J 2018;51. doi:10.1183/13993003.02604-2017. [Epub ahead of print: 10 May 2018].

2 Story A, van Hest R, Hayward A. Tuberculosis and social exclusion. BMJ 2006;333:57-8.

3 Story A. Epidemiology and control of tuberculosis in hard to reach groups in London. Amsterdam: Academic Medical Centre, University of Amsterdam, 2012

4 Gupta RK, Lipman M, Story A, et al. Active case finding and treatment adherence in risk groups in the tuberculosis pre-elimination era. Int J Tuberc Lung Dis 2018;22:479-87.

5 European Centre for Disease Prevention and Control. Interventions in vulnerable groups are the key to eliminating tuberculosis in Europe. Stockholm: ECDC, 2016.

6 Uplekar M, Weil D, Lonnroth K. WHO's Global TB Programme. WHO's new end TB strategy. Lancet 2015;385:1799-801.

7 Zenner D, Southern J, van Hest R, et al. Active case finding for tuberculosis among high-risk groups in low-incidence countries. Int $J$ Tuberc Lung Dis 2013;17:573-82.

8 European centre for disease prevention and Control/WHO regional office for Europe. Tuberculosis surveillance and monitoring in Europe 2020 - 2018 data. Stockholm: ECDC, 2020.

9 Golli A-L, Niţu MF, Turcu F, et al. Tuberculosis remains a public health problem in Romania. Int J Tuberc Lung Dis 2019;23:226-31.

10 Cioran NV, Mincă DG, Furtunescu FL. Aspects of monitoring a cohort of adult homeless people suffering from tuberculosis compared to the general population of Bucharest. Journal Plus Education 2015;12A:94-100.

11 de Vries G, van Hest RAH, Richardus JH. Impact of mobile radiographic screening on tuberculosis among drug users and homeless persons. Am J Respir Crit Care Med 2007;176:201-7.

12 Gliddon HD, Shorten RJ, Hayward AC, et al. A sputum sample processing method for community and mobile tuberculosis diagnosis using the Xpert MTB/RIF assay. ERJ Open Res 2019;5. doi:10.1183/23120541.00165-2018. [Epub ahead of print: 01 Feb 2019].

13 Melendez J, Hogeweg L, Sánchez Cl, et al. Accuracy of an automated system for tuberculosis detection on chest radiographs in high-risk screening. Int J Tuberc Lung Dis 2018;22:567-71.

14 Craig GM, Booth $\mathrm{H}$, Hall J, et al. Establishing a new service role in tuberculosis care: the tuberculosis link worker. J Adv Nurs 2008;61:413-24.

15 Breuninger M, van Ginneken B, Philipsen RHHM, et al. Diagnostic accuracy of computer-aided detection of pulmonary tuberculosis in chest radiographs: a validation study from sub-Saharan Africa. PLoS One 2014;9:e106381.

16 Munteanu I, Cioran N, van Hest R, et al. Tuberculosis surveillance in Romania among vulnerable risk groups 2015-2017. submitted.

17 The European Federation of National Organisations working with the Homeless (FEANTSA).. ETHOS Typology on homelessness and housing exclusion [internet]. [Internet. Brussels, Belgium: FEANTSA, 2011. https://www.feantsa.org/download/en16822651433655843804.pdf

18 European Monitoring Centre for Drugs and Drug Addiction. European drug report 2015: Data and statistics. Problem drug use: an overview of the methods and definitions used [Internet]. [Internet]. Lisbon: EMCDDA; 2015. Available: http://www.emcdda.europa.eu/data/ stats2015/methods-pdu

19 de Vries G, van Hest RA. From contact investigation to tuberculosis screening of drug addicts and homeless persons in Rotterdam. Eur J Public Health 2006;16:133-6.

20 Jit M, Stagg HR, Aldridge RW, et al. Dedicated outreach service for hard to reach patients with tuberculosis in London: observational study and economic evaluation. BMJ 2011;343:d5376.

21 Aldridge RW, Hayward AC, Hemming S, et al. High prevalence of latent tuberculosis and bloodborne virus infection in a homeless population. Thorax 2018;73:557-64.

22 Story A, Aldridge RW, Smith CM, et al. Smartphone-enabled videoobserved versus directly observed treatment for tuberculosis: a multicentre, analyst-blinded, randomised, controlled superiority trial. Lancet 2019;393:1216-24

23 Heuvelings CC, de Vries SG, Greve PF, et al. Effectiveness of interventions for diagnosis and treatment of tuberculosis in hardto-reach populations in countries of low and medium tuberculosis incidence: a systematic review. Lancet Infect Dis 2017;17:e144-58.

24 de Vries G, Gainaru D, Keizer S. Human reading versus computer automated reading of chest $\mathrm{X}$-rays in a tuberculosis screening programme in Romania. Eur Respir J2021. 
25 Qin ZZ, Sander MS, Rai B, et al. Using artificial intelligence to read chest radiographs for tuberculosis detection: a multi-site evaluation of the diagnostic accuracy of three deep learning systems. Sci Rep 2019;9:15000.

26 Philipsen RHHM, Sánchez Cl, Maduskar P, et al. Automated chestradiography as a triage for Xpert testing in resource-constrained settings: a prospective study of diagnostic accuracy and costs. $\mathrm{Sci}$ Rep 2015;5:12215.

27 Pande T, Cohen C, Pai M, et al. Computer-Aided detection of pulmonary tuberculosis on digital chest radiographs: a systematic review. Int J Tuberc Lung Dis 2016;20:1226-30. 